\title{
Clinical significance of interleukin-6 and inducible nitric oxide synthase in ketamine-induced cystitis
}

\author{
CHI-JUNG HUANG ${ }^{1,2}$, FA-KUNG LEE ${ }^{3,4}$, SHAO-KUAN CHEN ${ }^{3,5}$, CHIH-CHENG CHIEN ${ }^{1,3,6}$, \\ SHENG-TANG $\mathrm{WU}^{7}$ and YEN-CHIEH WANG ${ }^{3,5}$
}

\author{
${ }^{1}$ Department of Medical Research, Cathay General Hospital, Taipei 10630; ${ }^{2}$ Department of Biochemistry, \\ National Defense Medical Center, Taipei 11490; ${ }^{3}$ School of Medicine, College of Medicine, Fu Jen Catholic University, \\ New Taipei 24205; ${ }^{4}$ Department of Obstetrics and Gynecology, Cathay General Hospital, Taipei 10630; \\ ${ }^{5}$ Department of Surgery, Sijhih Cathay General Hospital, New Taipei 22174; ${ }^{6}$ Department of Anesthesiology, \\ Cathay General Hospital, Taipei 10630; ${ }^{7}$ Division of Urology, Department of Surgery, \\ Tri-Service General Hospital, National Defense Medical Center, Taipei 11490, Taiwan, R.O.C.
}

Received April 18, 2016; Accepted October 30, 2017

DOI: $10.3892 / \mathrm{ijmm} .2017 .3264$

\begin{abstract}
Ketamine is an ionotropic glutamatergic $\mathrm{N}$-methyl-D-aspartate receptor antagonist, which is widely used among recreational drug abusers. Ketamine abusers exhibit substantially reduced bladder capacity, which can lead to urinary frequency. The molecular pathogenesis of ketamine-induced cystitis has been scarcely reported. Given previous clinical findings, it may be hypothesized that pathological alterations in smooth muscle cells (SMCs) of the urinary bladder serve a crucial role in the mechanism underlying cystitis. In the present study, two lineages of SMCs, one from differentiated foreskin-derived fibroblast-like stromal cells and the other from cultured normal aortic SMCs, were used to study ketamine-induced molecular alterations. Polymerase chain reaction was used to study the effects of ketamine on oxidative stress. The effects of adjuvant chemotherapy with cyclophosphamide (CTX) were also investigated. The results indicated that the expression levels of interleukin- 6 and inducible nitric oxide synthase (iNOS) were decreased, whereas collagen expression and deposition were increased
\end{abstract}

Correspondence to: Dr Yen-Chieh Wang, Department of Surgery, Sijhih Cathay General Hospital, No. 2, Ln. 59 Jiancheng Road, Sijhih, New Taipei 22174, Taiwan, R.O.C.

E-mail: ycwangurology@gmail.com

Abbreviations: SMCs, smooth muscle cells; FDSCs, foreskin-derived fibroblast-like stromal cells; NMDA, N-methyl-D-aspartate; PCR, polymerase chain reaction; qPCR, quantitative PCR; TGF- $\beta 1$, transforming growth factor- $\beta 1$; PDGF-BB, platelet-derived growth factor-BB; CTX, cyclophosphamide; IF, immunofluorescent; COL1, type I collagen; COL2, type II collagen; IL-6, interleukin-6; iNOS, inducible nitric oxide synthase; FITC, fluorescein isothiocyanate; TTN, titin

Key words: ketamine-induced cystitis, smooth muscle cells, interleukin-6, inducible nitric oxide synthase, cyclophosphamide in ketamine-treated SMCs. Conversely, treatment with CTX restored the expression of iNOS, which may prevent or limit oxidative damage. In conclusion, the present study demonstrated that ketamine may induce several molecular alterations in SMCs and these changes may be associated with the clinical symptoms observed in ketamine abusers. In addition, the specific chemotherapeutic agent CTX may reverse these ketamine-induced aberrations.

\section{Introduction}

Ketamine, which is an ionotropic glutamatergic $\mathrm{N}$-methyl-D-aspartate (NMDA) receptor antagonist, can produce a fast-acting antidepressant response in patients with major depressive disorder (1-3). Ketamine is used clinically for pediatric anesthesia and sedation, as an anesthetic in the treatment of asthma, and in pain management $(4,5)$. In addition, ketamine, in liquid or powdered form, is a widely used recreational drug that can be injected, ingested or added to materials for smoking (6,7). The Drug Enforcement Administration of Taiwan categorizes ketamine as a Schedule III substance due to its illegal abuse.

Although ketamine rarely produces serious withdrawal symptoms, it does exert dose-dependent psychedelic and psychotic effects $(8,9)$. In addition to its neurotoxic effects, ketamine affects other cell lineages due to its role as an NMDA receptor antagonist (10). For example, ketamine abuse can induce cystitis and cause serious damage to the urinary tract $(11,12)$. Ketamine abusers may experience urinary frequency, urgency, dysuria, urge incontinence, hemorrhagic cystitis and hydronephrosis (13-15). In long-term ketamine abusers, bladder capacity may decrease substantially to one-tenth of the primary capacity $(13,16,17)$. Major surgical operations, including augmentation ileocystoplasty, have been reported to efficaciously relieve refractory ketamine-associated bladder pain and to reduce urinary tract symptoms $(7,18)$. In addition to surgery, chondroitin sulfate therapy can relieve symptoms of severe ketamine-induced contracted bladder (19). 
In addition, transformation of the bladder wall and increased interstitial fibrosis in the bladder tissue have been observed in rats following long-term ketamine administration $(7,20,21)$.

The mechanism underlying bladder contracture, a serious ketamine-induced side effect, remains unclear. Previous studies have suggested that clinical manifestations induced by ketamine may be mediated through a specific neurogenic mechanism or possible hypersensitivity $(18,22)$. Furthermore, clinical data have suggested the involvement of chronic inflammation and epithelial repair in this lower urinary tract symptom (22-24). The side effects of ketamine abuse have emerged as a novel challenge for urologists (16).

Given the previous clinical findings, it may be hypothesized that pathological alterations in smooth muscle cells (SMCs) of the urinary bladder serve a crucial role in the mechanism underlying ketamine-induced cystitis. The present study used two lineages of SMCs, one from differentiated foreskin-derived fibroblast-like stromal cells (FDSCs) and the other from cultured normal aortic SMCs, to investigate ketamine-induced molecular alterations. Immunocytochemical staining was used to examine the effects of ketamine on differentiated FDSCs and cell viability. To determine the effects of ketamine on oxidative stress (25), polymerase chain reaction (PCR) array-based expression profiling was conducted. The ketamine-induced molecular alterations were subsequently validated using quantitative (q)PCR or western blot analysis. An understanding of the molecular alterations involved in ketamine-associated bladder dysfunction may contribute to the development of adjuvant therapy for ketamine abusers.

\section{Materials and methods}

Differentiation of human FDSCs to SMCs and cultivation of normal aortic SMCs. SMCs from two different lineages, FDSC-derived SMCs and cultured human normal aortic SMCs, were used to evaluate the effects of ketamine. Initially, FDSCs were harvested from foreskin tissues. This protocol was approved by the institutional review board of Cathay General Hospital (CGH-P100084). To differentiate isolated stromal cells into SMCs, FDSCs were cultivated in complete Dulbecco's modified Eagle's medium (\#12100046; Thermo Fisher Scientific, Inc., Waltham, MA, USA) on fibronectin-coated culture plates, supplemented with two growth factors, transforming growth factor (TGF)- $\beta 1(2.5 \mathrm{ng} / \mathrm{ml})$ (\#240-B; R\&D Systems, Inc., Minneapolis, MN, USA) and platelet-derived growth factor-BB (PDGF-BB, $5 \mathrm{ng} / \mathrm{ml}$ ) (\#220$\mathrm{BB} ; \mathrm{R} \& \mathrm{D}$ Systems, Inc.) in a humidified incubator at $37^{\circ} \mathrm{C}$ and $5 \% \mathrm{CO}_{2}$, for 5-10 passages within 4 weeks (26-28). In addition, human normal aortic SMCs [American Type Culture Collection (ATCC) CRL-1999] were cultured in ATCC-formulated F-12K medium (ATCC \#30-2004; both ATCC, Manassas, VA, USA) at $37^{\circ} \mathrm{C}$ in an incubator containing $5 \% \mathrm{CO}_{2}$ with extra components $[0.05 \mathrm{mg} / \mathrm{ml}$ ascorbic acid; $0.01 \mathrm{mg} / \mathrm{ml}$ insulin; $0.01 \mathrm{mg} / \mathrm{ml}$ transferrin; $10 \mathrm{ng} / \mathrm{ml}$ sodium selenite; $0.03 \mathrm{mg} / \mathrm{ml}$ endothelial cell growth supplement; $10 \%$ fetal bovine serum; $10 \mathrm{mM}$ (4-(2-hydroxyethyl)-1-piperazineethanesulfonic acid); $10 \mathrm{mM}$ TES] suggested by the manufacturer.

Treatment of SMCs with ketamine and cyclophosphamide $(C T X)$. To determine the effects of ketamine on normal
SMCs, the concentration of residual ketamine $(7.744 \mu \mathrm{g} / \mathrm{ml})$ in the urinary bladder was used as a reference concentration in the direct treatment of FDSC-derived SMCs and human normal aortic SMCs (7). FDSC-derived SMCs were subjected to cyclic ketamine treatment. The prescription license for the use of ketamine (Ketalar Injection; Pfizer Ltd., Surrey, UK) in the present study was permitted by the Food and Drug Administration of the Ministry of Health and Welfare in Taiwan (announcement no. 1000088118; Taipei, Taiwan, R.O.C.) and by Cathay General Hospital (announcement no. CRM09500000101; Taipei, Taiwan, R.O.C.). One cycle of ketamine treatment comprised incubation of SMCs in a growth factor-containing medium with various doses of ketamine $(0$, 1 and $10 \mu \mathrm{g} / \mathrm{ml}$ ) for 1 day, followed by a 1 day culture without ketamine, both at $37^{\circ} \mathrm{C}$. In an additional experiment, cultured human normal aortic SMCs were incubated with the chemotherapeutic agent CTX $(10 \mu \mathrm{M})$ (Endoxan Injection; Baxter Deutschland $\mathrm{GmbH}$, Unterschleißheim, Germany) for $5 \mathrm{~h}$ following 1-day ketamine $(10 \mu \mathrm{g} / \mathrm{ml})$ treatment at $37^{\circ} \mathrm{C}(29)$.

Immunodetection of smooth muscle actin (SMA), collagens, interleukin (IL)-6 and inducible nitric oxide synthase (iNOS). For a comprehensive study, immunocytochemical and immunofluorescent (IF) staining, and western blot analysis were performed on FDSC-derived SMCs and normal aortic SMCs treated with various concentrations of ketamine. Briefly, cells on glass slides were fixed with $4 \%$ paraformaldehyde in phosphate-buffered saline for $5 \mathrm{~min}$ and were then permeabilized with $0.1 \%$ Triton $\mathrm{X}-100$ for $20 \mathrm{~min}$ at room temperature. To ensure the differentiation efficacy of the FDSCs, SMA was detected by incubating the slides with undiluted anti-SMA antibody (\#IR611) for $30 \mathrm{~min}$ at room temperature, and staining was developed using a Dako REAL detection system (\#K4065) (both Agilent Technologies, Inc., Santa Clara, CA, USA) according to the manufacturer's protocols. IF staining was used to detect type II collagen (COL2), IL-6 and iNOS expression. Briefly, COL2 was detected by incubating the FDSC-derived ketamine-treated SMCs with anti-COL2 (MAB1330, 1:5) for $12 \mathrm{~h}$ at $4^{\circ} \mathrm{C}$ and fluorescein isothiocyanate (FITC)-conjugated anti-mouse immunoglobulin (Ig)G (AP192F, 1:200) for $1 \mathrm{~h}$ at $25^{\circ} \mathrm{C}$ (both EMD Millipore, Billerica, MA, USA).

To identify alterations in IL-6 and iNOS expression following CTX $(0$ or $10 \mu \mathrm{M})$ and ketamine $(0$ or $10 \mu \mathrm{g} / \mathrm{ml})$ treatment, normal aortic SMCs were subjected to IF immunostaining. Briefly, SMA was detected using anti-SMA (sc-1616, 1:50; Santa Cruz Biotechnology, Inc., Dallas, TX, USA) and FITC-conjugated anti-goat IgG (\#02-13-06, 1:200; KPL, Inc., Gaithersburg, MD, USA). Anti-IL-6 (ab6672, 1:500) and anti-iNOS (ab3523, 1:20) (both Abcam, Cambridge, UK) were used to colocalize SMA with IL-6 and iNOS, respectively, and Cy3-conjugated anti-rabbit IgG was used as a secondary antibody (AP182C, 1:200; EMD Millipore). The incubation time for all primary antibodies was $12 \mathrm{~h}$ at $4^{\circ} \mathrm{C}$ and for secondary antibodies was $1 \mathrm{~h}$ at $25^{\circ} \mathrm{C}$. Finally, the nuclei were identified by counterstaining with 4',6-diamidino-2-phenylindole. The stained samples were dehydrated, mounted and analyzed using a Nikon Eclipse 80i fluorescence microscope (Nikon Instruments Europe BV, Amsterdam, The Netherlands).

Western blot analysis was performed to detect COL1 expression in FDSC-derived SMCs that underwent various 
Table I. Probes and primer sequences for quantification of $I L-6, T G F-\beta 1$ and $C O X-2$.

\begin{tabular}{|c|c|c|c|}
\hline $\begin{array}{l}\text { Gene } \\
\text { name }\end{array}$ & Accession no. & Sequence $\left(5^{\prime}-3^{\prime}\right)$ & $\begin{array}{c}\text { Probe } \\
\text { no. }\end{array}$ \\
\hline$I L-6$ & NM_000600 & $\begin{array}{l}\text { F: gatgagtacaaaagtcctgatcca } \\
\text { R: ctgcagccactggttctgt }\end{array}$ & 40 \\
\hline$T G F-\beta 1$ & NM_000660 & $\begin{array}{l}\text { F: tggacacgcagtacagcaa } \\
\text { R: cttgcggcccacgtagta }\end{array}$ & 11 \\
\hline$C O X-2$ & AY462100 & $\begin{array}{l}\text { F: gctttatgctgaagcctatga } \\
\text { R: tccaactctgcagacatttcc }\end{array}$ & 2 \\
\hline GAPDH & NM_002046 & $\begin{array}{l}\text { F: ctctgctcctcctgttcgac } \\
\text { R: acgaccaaatccgttgactc }\end{array}$ & 60 \\
\hline
\end{tabular}

COX-2, cyclooxygenase-2; F, forward; IL-6, interleukin-6 ; R, reverse; $T G F-\beta 1$, transforming growth factor- $\beta 1$.

numbers of ketamine treatment cycles according to the standard protocol. Briefly, cell lysates were prepared using a radioimmunoprecipitation assay buffer (Intron Biotechnology, Inc., Seongnam, South Korea) and quantified using Bio-Rad Protein Assay kit II (\#5000002; Bio-Rad Laboratories, Inc., Hercules, CA, USA), according to the manufacturers' protocols. The protein aliquot $(30 \mu \mathrm{g})$ of each lysate was separated by $12 \%$ SDS-PAGE and was transferred to a polyvinylidene fluoride membrane using a TE70 semidry transfer unit (GE Healthcare Life Sciences, Little Chalfont, UK). The membrane was blocked in 3\% bovine serum albumin (\#A3803; Merck KGaA, Darmstadt, Germany) for $1 \mathrm{~h}$ at $25^{\circ} \mathrm{C}$, and COL1 was immunoblotted using anti-COL1 (ab292, 1:5,000; Abcam) for $1 \mathrm{~h}$ at $25^{\circ} \mathrm{C}$. Anti-GAPDH (AM4300, 1:4,000; Thermo Fisher Scientific, Inc.) was used as a protein-loading control to ensure equal protein levels in all samples (incubation time, $1 \mathrm{~h}$ at $25^{\circ} \mathrm{C}$ ). The secondary antibodies used were as follows: Biotinylated anti-rabbit IgG (BA-1000, 1:1,000; Vector Laboratories, Inc., Burlingame, CA, USA) for COL1 (30 min at $25^{\circ} \mathrm{C}$ ) and horseradish peroxidase-conjugated anti-mouse IgG for GAPDH $\left(1 \mathrm{~h}\right.$ at $25^{\circ} \mathrm{C}$ ) (AP192P, 1:5,000; EMD Millipore). The bands were visualized using a VECTASTAIN ABC-AmP Chemiluminescence Detection kit (AK-6601; Vector Laboratories, Inc.) for COL1 $\left(10 \mathrm{~min}\right.$ at $\left.25^{\circ} \mathrm{C}\right)$ and Western Lightning Plus-ECL (\#NEL103001EA; PerkinElmer, Inc., Waltham, MA, USA) for GAPDH, according to the manufacturers' protocols. Finally, images were captured using an Alpha Innotech FluorChem FC2 Imager (ProteinSimple, San Jose, CA, USA). Each protein band was recorded using UVP Bioimaging systems (UVP, LLC, Upland, CA, USA). The relative protein expression levels of COL1 normalized to GAPDH were identified by densitometry using ImageQuant, version 5.2 (Molecular Dynamics Inc, Chatsworth, CA, USA) and are expressed as the mean \pm standard deviation.

Molecular alterations induced by ketamine in FDSC-derived SMCs. Total RNA was isolated from FDSC-derived SMCs treated with or without ketamine, using TRI Reagent (T9424; Sigma-Aldrich; Merck KGaA). RNA was reverse transcribed to cDNA using oligo(dT) primer and a PowerScript ${ }^{\circledR}$ Reverse
Transcriptase kit (Invitrogen; Thermo Fisher Scientific, Inc.) following appropriate DNA digestion (AM2222; Thermo Fisher Scientific, Inc.), according to the manufacturers' protocols.

The inflammatory response and oxidative stress are believed to be involved in ketamine-associated cystitis. The present study examined the effects of ketamine on the differential expression of inflammation and oxidative stress markers in FDSC-derived SMCs with or without ketamine treatment $(10 \mu \mathrm{g} / \mathrm{ml})$ by comparing their expression levels. The relative mRNA expression levels of specific inflammatory markers were quantified using a gene expression assay with universal TaqMan probes in a LightCycler 1.5 system (both Roche Diagnostics, Basel, Switzerland). Primer sequences are listed in Table I. The thermocycling conditions were as follows: IL-6, TGF- $\beta 1, \mathrm{COX}-2$, and GAPDH were pre-incubated $\left(95^{\circ} \mathrm{C}\right.$ for $5 \mathrm{~min})$ and amplified $\left(95^{\circ} \mathrm{C}\right.$ for $10 \mathrm{sec}, 60^{\circ} \mathrm{C}$ for $\left.30 \mathrm{sec}\right)$ for 55 cycles. To detect ketamine-induced oxidative stress, an $\mathrm{RT}^{2}$ Profiler ${ }^{\mathrm{TM}}$ PCR array (Human Oxidative Stress Plus, PAHS-065Y; Qiagen N.V., Venlo, The Netherlands) was used with an Applied Biosystems 7300 Real-Time PCR system (Thermo Fisher Scientific, Inc.), according to the manufacturers' protocols.

The data were analyzed using software supplied by Qiagen $\left(\mathrm{RT}^{2}\right.$ Profiler $^{\mathrm{TM}}$ PCR Array Data Analysis, version 3.5) and were normalized to the expression of five internal housekeeping genes: $\beta$-actin, NM_001101; $\beta$-2-microglobulin, NM_004048; GAPDH, NM_002046 and the comparative $2^{-\Delta \Delta C q}$ method was used to analyze the relative changes in gene expression; hypoxanthine phosphoribosyltransferase 1, NM_000194; and ribosomal protein lateral stalk subunit P0, NM_001002. The significant targets [code numbers for titin (TTN): PPH06931F and $i N O S$ : PPH00173F] were validated using a specific $\mathrm{RT}^{2}$ qPCR primer assay (Qiagen N.V.) with the Applied Biosystems 7300 Real-Time PCR system. Dissociation curves were analyzed after each reaction to assess the quantification specificity in the $\mathrm{RT}^{2} \mathrm{qPCR}$ primer assay. Each quantification was calculated relative to the level of an endogenous control, GAPDH (NM_002046). Those showing changes in specific genes $>2$-fold were considered significant candidates.

Statistical analysis. The Student's t-test was used to compare the significant differences in gene expression between different groups. All statistical analyses were performed using SPSS software (v. 22.0; IBM Corp., Armonk, NY, USA). The data shown here are representative of at least three experiments with similar results, and P-values $<0.05$ are considered significant.

\section{Results}

Deformation of FCSC-derived SMCs by ketamine. The effects of ketamine on human SMCs were studied using FDSC-derived SMCs and normal aortic SMCs. Differentiation of FDSCs into SMCs was confirmed by the positive signals observed by immunostaining with an anti-SMA antibody (Fig. 1A). The FDSC-derived SMCs shrank and deformed into a spindle shape when treated with $10^{2} \mu \mathrm{g} / \mathrm{ml}$ ketamine. Based on our observations of the molecular effects of ketamine on the urinary bladder (7) and the marginal concentra- 

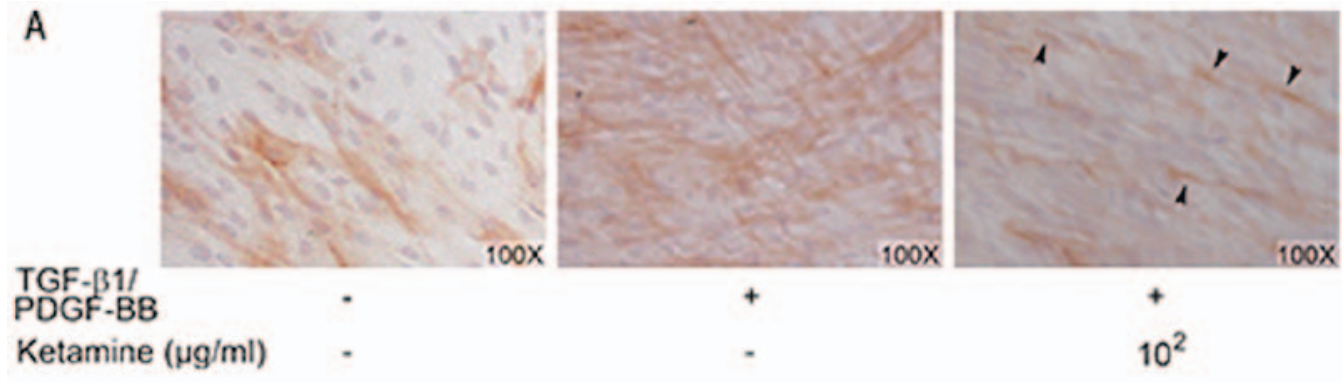

\section{B}
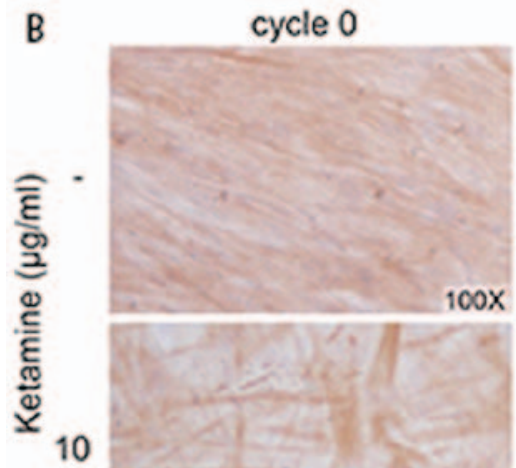

cycle 0 $100 \mathrm{X}$
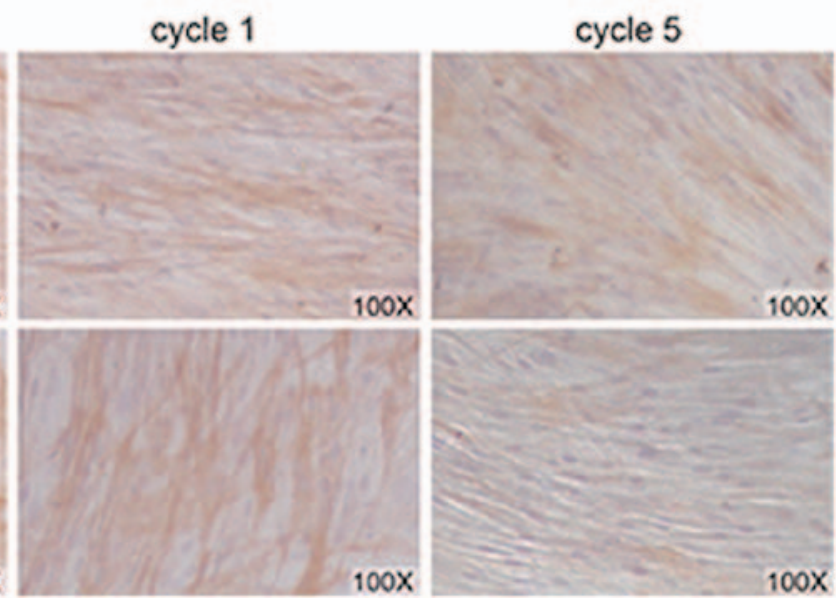

Figure 1. Immunodetection of SMA from human FDSC-derived SMCs treated with ketamine. (A) SMA expression in human FDSC-derived SMCs treated with ketamine. Isolated foreskin cells were harvested, seeded on fibronectin-coated culture plates and were then treated with (+) or without (-) the myogenic differentiation agent, containing TGF- $\beta 1(2.5 \mathrm{ng} / \mathrm{ml})$ and PDGF-BB $(5 \mathrm{ng} / \mathrm{ml})$. After a 14-day incubation for differentiation, cells were treated with $\left(10^{2} \mu \mathrm{g} / \mathrm{ml}\right)$ or without (-) ketamine for 5 days. Arrow heads represent cells with spindle shape. (B) Morphological alterations of human FDSC-derived SMCs following cyclic ketamine treatment. All isolated cells were treated with the myogenic differentiation agent followed by treatment with (10 $\mu \mathrm{g} / \mathrm{ml})$ or without (-) ketamine for various cycles (0,1 and 5 cycles). Each cycle composed 1 day ketamine treatment and 1 day of culturing in medium alone. The cells were fixed and incubated with anti-SMA. FDSC, foreskin-derived fibroblast-like stromal cells; PDGF-BB, platelet-derived growth factor-BB; SMA, smooth muscle actin; TGF- $\beta 1$, transforming growth factor- $\beta 1$.

tion of ketamine detected in the urine of ketamine abusers, $10 \mu \mathrm{g} / \mathrm{ml}$ was selected as the concentration for cyclic treatment of SMCs $(30,31)$. Compared with untreated FDSC-derived SMCs, cells grew to achieve a spindle-like morphology with additional cycles of ketamine treatment (Fig. 1B).

Collagen expression and deposition is increased in FDSC-derived SMCs following ketamine treatment. To investigate whether fibrosis is induced in FDSC-derived ketamine-treated SMCs, the protein expression levels of frequently studied collagens, COL1 and COL2, were detected. Western blot analysis demonstrated that COL1, which is associated with fibrosis, was decreased in FDSC-derived SMCs (Fig. 2A). This decrease was prevented in cells exposed to cyclic ketamine treatment. Densitometric analysis was used to semi-quantify the relative expression levels of COL1; the protein expression levels of COL1 were increased with increasing cycles (Fig. 2B). COL2 deposition around cell nuclei in the cytosol of FDSC-derived SMCs was identified after 5 cycles of ketamine treatment. Obvious COL2 deposition appears increased in ketamine-treated cells (Fig. 2C), not in cells treated with TGF- $\beta 1$ and PDGF-BB only (Fig. 2D).

Detection of altered mRNA expression in FDSC-derived SMCs following ketamine treatment. Molecular alterations were detected in cells following cyclic ketamine treatment.
Cyclooxygenase-2 levels were increased and $I L-6$ levels were decreased, whereas $T G F-\beta 1$ levels were not markedly altered after 5 cycles of ketamine treatment in FDSC-derived SMCs (Fig. 3A). The mRNA expression levels of $I L-6$ were increased when the concentration of ketamine was lowered from 10 to $1 \mu \mathrm{g} / \mathrm{ml}$ during cyclic ketamine treatment (Fig. 3B). A pathway-focused PCR array was used to examine oxidative stress; the results indicated that the expression levels of two genes associated with oxidative stress, TTN (NM_003319) and iNOS (NM_000625), were significantly reduced, with fold-changes of 0.41 and 0.29 , respectively, in FDSC-derived SMCs following 8 cycles of ketamine treatment (Fig. 4A). All other genes exhibited fold-changes within the range of 0.5 and 2.0. However, only $i N O S$ was downregulated (0.25-fold) after repeated ketamine treatment, as determined by specific qPCR validation in FDSC-derived SMCs (Fig. 4B). The mRNA expression levels of $i N O S$ were restored when the concentration of ketamine was decreased from 10 to $1 \mu \mathrm{g} / \mathrm{ml}$ during cyclic ketamine treatment (Fig. 4C).

Restoration of protein levels of IL- 6 and iNOS by CTX in ketamine-treated normal aortic SMCs. Similar to the results presented in Fig. 1B, normal aortic SMCs also became deformed and exhibited a spindle-like morphology following treatment with $10 \mu \mathrm{g} / \mathrm{ml}$ ketamine for $24 \mathrm{~h}$ (Fig. 5). All SMCs expressed consistent levels of SMA (labeled green with FITC 


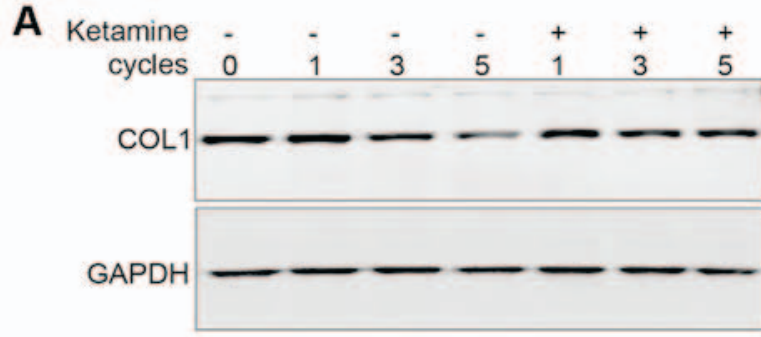

\section{C}

TGF- $\beta 1+P D G F-B B$

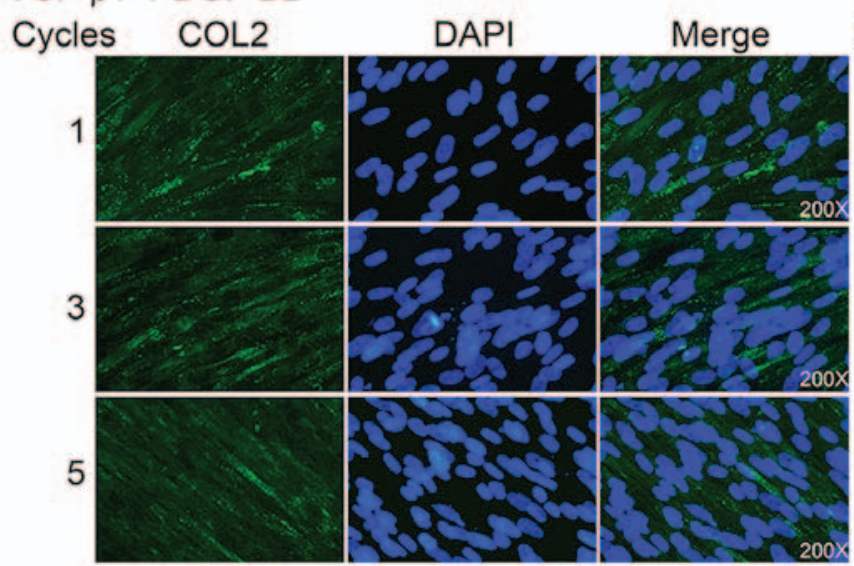

B

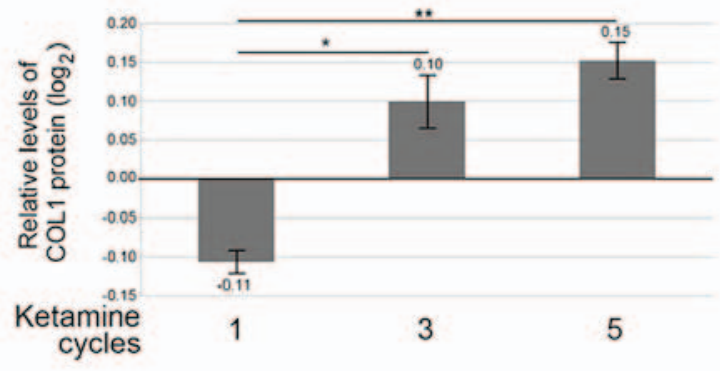

D

TGF- $\beta 1+P D G F-B B /$ Ketamine
DAPI

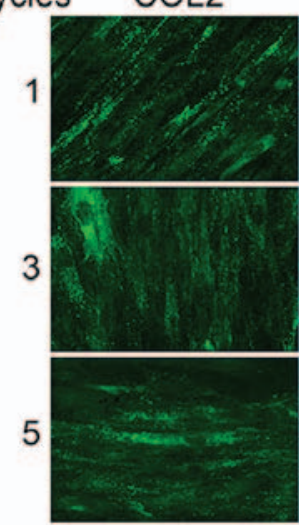

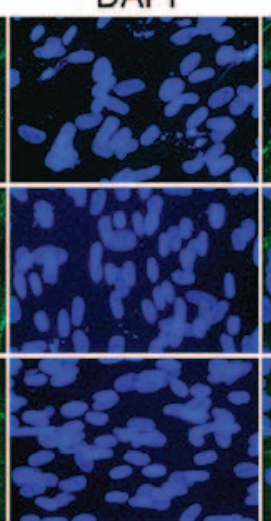

Merge

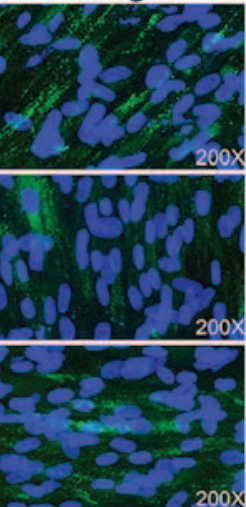

Figure 2. Immunodetection of collagens from human foreskin-derived stromal cells following cyclic ketamine treatment. (A) Detection of COL1. (B) Semi-quantification of immunoblotting. Expression was semi-quantified to GAPDH and $\log _{2}$ values were calculated. ${ }^{*} \mathrm{P}<0.05$ and ${ }^{* *} \mathrm{P}<0.01$. (C) Fluorescent detection of COL2 from cells without ketamine treatment. (D) Fluorescent detection of COL2 from cells following ketamine treatment. Isolated cells were harvested and seeded on fibronectin-coated culture plates and were then treated with the myogenic differentiation agent, containing TGF- $\beta 1$ ( $2.5 \mathrm{ng} / \mathrm{ml})$ and PDGF-BB $(5 \mathrm{ng} / \mathrm{ml})$. After a 14-day incubation for differentiation, cells were treated with (+) or without (-) ketamine $(10 \mu \mathrm{g} / \mathrm{ml})$ for various cycles $(1,3$ and 5 cycles). Each cycle composed 1 day ketamine treatment followed by 1 day culturing in medium alone. COL1, type I collagen; COL2, type II collagen; DAPI, 4',6-diamidino-2-phenylindole; PDGF-BB, platelet-derived growth factor-BB; TGF- $\beta 1$, transforming growth factor- $\beta 1$.

A

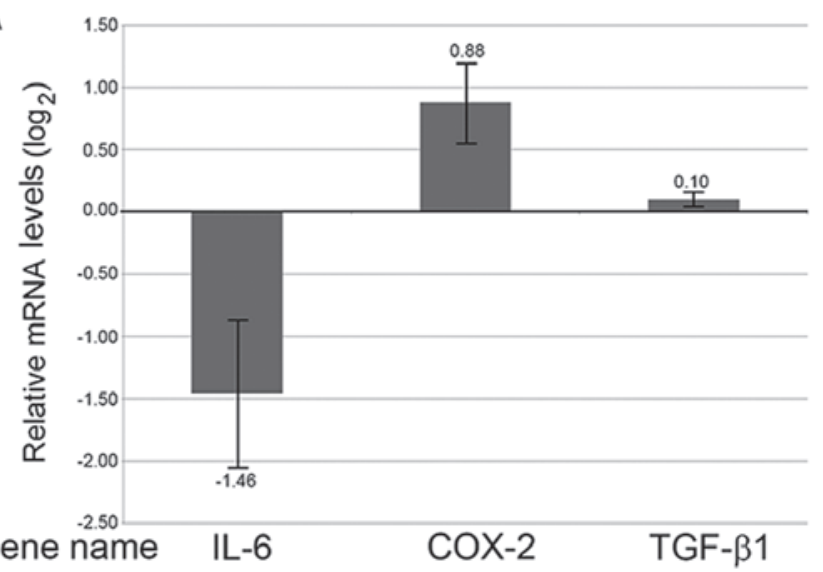

B

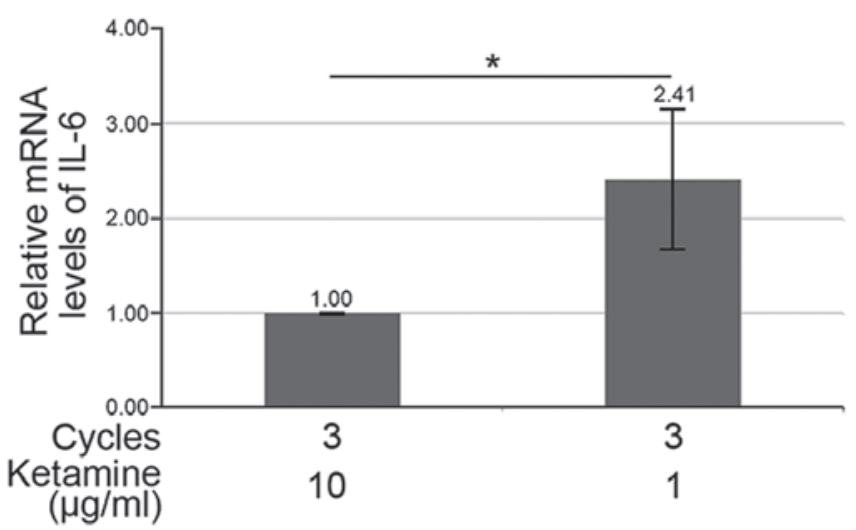

Figure 3. Detection of molecular alterations in cells following cyclic ketamine treatment. (A) Relative mRNA expression levels of $I L-6, C O X-2$ and $T G F-\beta 1$ in cells following 5 cycles of ketamine treatment. (B) Alterations in the mRNA expression levels of $I L-6$ from cells following 3 cycles of ketamine treatment. All mRNA levels were quantified by quantitative polymerase chain reaction and were relatively obtained by dividing the mRNA levels of cells with cyclic ketamine treatment by those of cells without any treatment. ${ }^{*} \mathrm{P}<0.05$. $C O X-2$, cyclooxygenase- $2 ; I L-6$, interleukin- 6 ; $T G F-\beta 1$, transforming growth factor- $\beta 1$.

in the figure); however, reduced levels of IL-6 and iNOS (both labeled red with $\mathrm{Cy} 3$ ) were detected following ketamine treatment (Fig. 5). Conversely, the levels of IL-6 and iNOS were restored following $10 \mu \mathrm{M}$ CTX treatment (Fig. 5).

\section{Discussion}

Ketamine abusers exhibit numerous clinical symptoms (32). Typically, long-term ( $>2$ years) ketamine abuse results in 

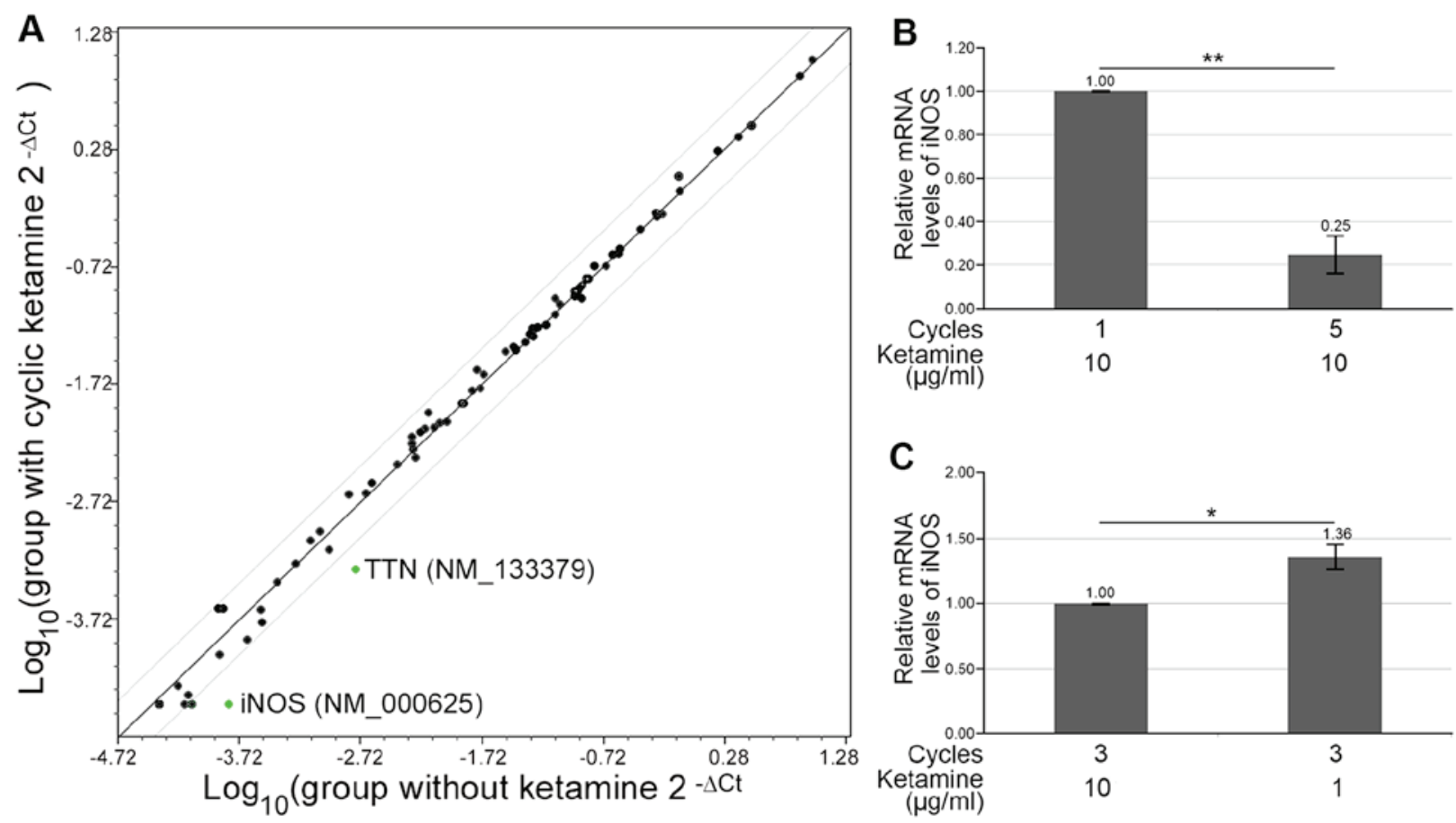

Figure 4. Genes correlated with ketamine-induced oxidative stress. (A) Scatter plot of the expression of 84 candidate genes associated with oxidative stress. Green dots indicate downregulated genes in cells with cyclic ketamine treatment compared with the group without ketamine treatment. The central line indicates unaltered gene expression; boundaries represent the 2-fold regulation cut-off. (B) Relative mRNA expression levels of $i N O S$ in cells following 5 cycles of ketamine treatment. (C) Alterations in iNOS mRNA expression from cells following 3 cycles of ketamine treatment. mRNA expression levels were quantified by quantitative polymerase chain reaction and were relatively obtained by dividing the mRNA levels of cells with cyclic ketamine treatment by those of cells without any treatment. ${ }^{*} \mathrm{P}<0.05$ and ${ }^{* *} \mathrm{P}<0.01$. TTN, titin $\left(\mathrm{NM} \_003319\right)$; iNOS, inducible nitric oxide (NM_000625).

bilateral lower ureteral stricture and a contracted bladder with severely reduced bladder capacity $(<55 \mathrm{ml})(33,34)$. Clinical observations include urinary frequency (average, $>31$ times/day) and nocturia (12.5 times/day) in ketamine abusers due to their reduced bladder capacity (7). In addition, genetic alterations have been observed in ketamine-induced cystitis $(35,36)$. However, to the best of our knowledge, no translational study has indicated any potential therapy for these pathological and molecular alterations in the ketamine-injured human bladder.

Although ketamine-induced cystitis can cause bladder pain, which is mediated through a specific neurogenic mechanism on the urothelium, we proposed that the main muscle component of the urinary bladder wall, the detrusor muscle, is also damaged by ketamine $(22,37,38)$. However, dynamic genetic alterations involving irreversible bladder contracture in the human detrusor muscle are difficult to analyze in ketamine abusers. Therefore, two types of cultured normal human SMCs, FDSC-derived SMCs and aortic SMCs, were used in the present study to evaluate in vitro ketamine-induced molecular alterations.

Ketamine and its active metabolites (e.g., norketamine) are believed to exert a direct toxic effect on the bladder mucosa $(17,35)$. In the cultured normal SMCs used in the present study, ketamine, but not norketamine, induced a cytotoxic effect on cell growth (data not shown). Similarly, ketamine has been reported to exert toxicity in chondrocyte cell cultures and induce cytoskeleton interruption $(39,40)$. Collectively, these results suggested that ketamine may dose-dependently damage the urinary bladder and affect SMC stability. This is consistent with the findings of Shahani et al who reported that severe ulcerative cystitis results from chronic ketamine use (13). Since 1998, mouse models have been used to demonstrate that accelerated fibrosis and collagen deposition coincide in the renal interstitium during ureteral obstruction (41). Furthermore, a rat model has been used to indicate that ketamine increases interstitial fibrosis in urinary bladder tissues $(20,42,43)$. Increased fibrosis can be examined by measuring the deposition of various types of collagen (44), and excessive synthesis of COL1 and COL2 indicates fibrosis in various organs $(45,46)$. The excessive COL1 and COL2 levels detected in response to ketamine in the present study suggested that fibrosis occurs in ketamine-treated normal human SMCs.

The expression of IL-6, which is an IL with pleiotropic functions as a proinflammatory cytokine and an anti-inflammatory myokine (47), was reduced following cyclic ketamine treatment in the present study. However, some inflammatory markers were upregulated in our previous model of ketamine-induced cystitis $(35,42)$. Given the present data and those of previous studies, it may be concluded that inflammatory markers are expressed differently between various types of ketamine-treated cells (48). Numerous studies regarding antidepressants and neural pathways have indicated that ketamine is associated with the downregulation of proinflammatory cytokines, including IL-6 $(36,49)$. In addition, the expression of IL- 6 was positively correlated with the migration of vascular SMCs (50). Therefore, reduced IL-6 expression in ketamine-treated SMCs may be associated with the function of IL- 6 as an anti-inflammatory myokine, 

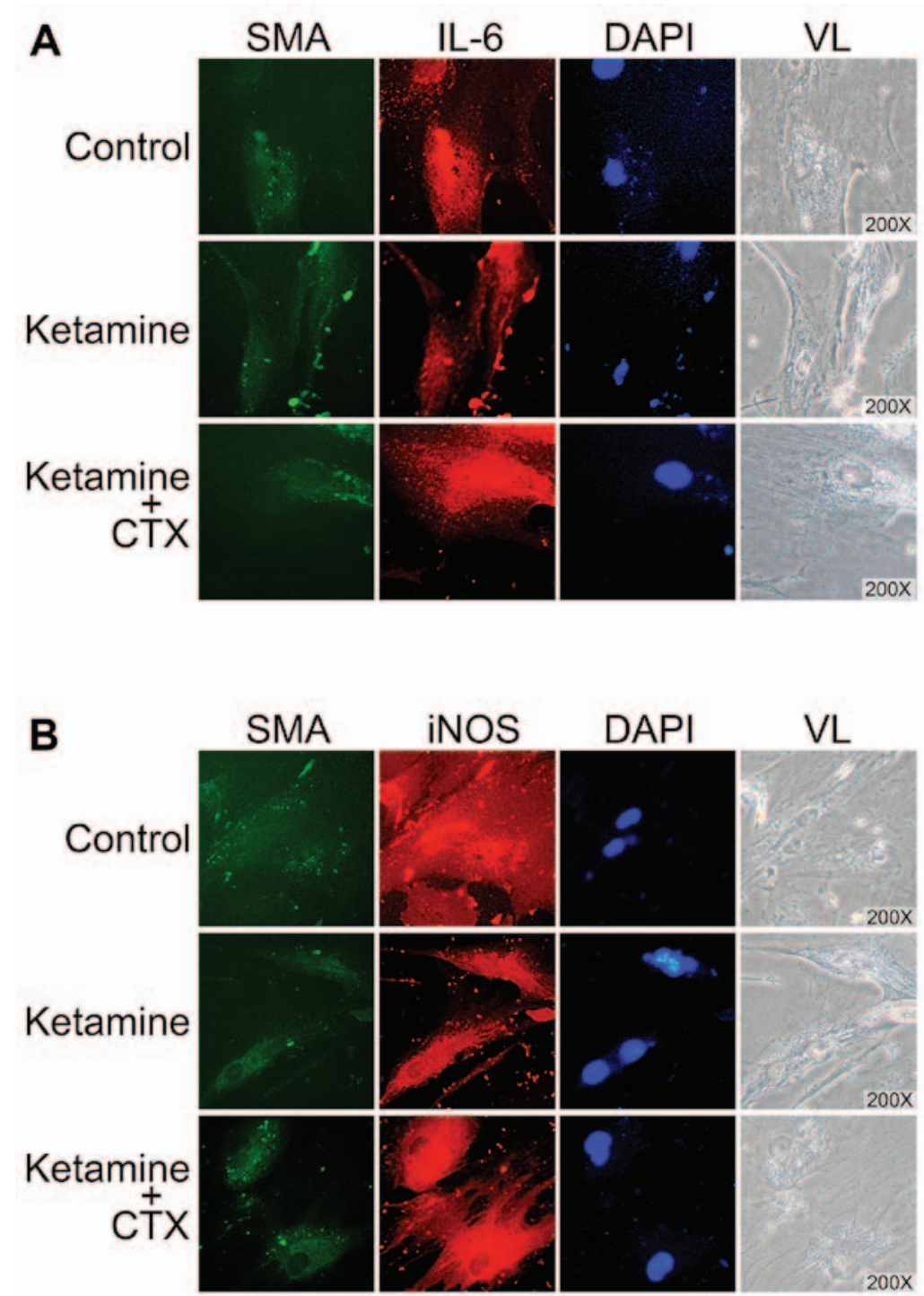

Figure 5. Ketamine-induced molecular alterations in normal aortic SMCs, and the effects of CTX. (A) IL-6 and (B) iNOS expression was restored with CTX treatment. Normal aortic SMCs were treated with $10 \mu \mathrm{g} / \mathrm{ml}$ ketamine alone or in combination with $10 \mu \mathrm{M}$ cyclophophamide. Nuclei were stained with DAPI CTX, cyclophosphamide; DAPI, 4',6-diamidino-2-phenylindole; IL-6, interleukin-6; iNOS, nitric oxide synthase 2; SMA, smooth muscle actin; SMCs, smooth muscle cells; VL, visible light.

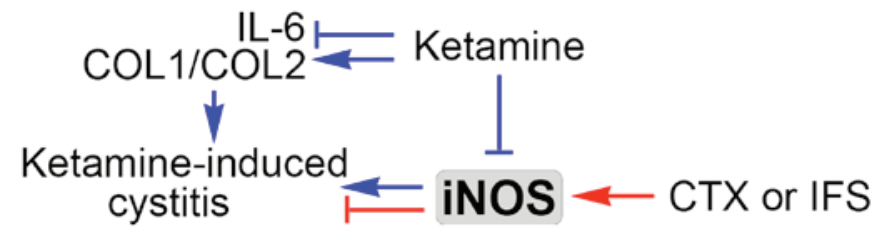

Figure 6. Molecular pathogenesis of ketamine-induced cystitis. Red lines or arrows indicate effects of CTX or IFS; blue lines or arrows indicate effects of ketamine. COL1, type I collagen; COL2, type II collagen; CTX, cyclophosphamide; IFS, ifosfamide; IL-6, interleukin-6; iNOS, nitric oxide synthase 2.

thus suggesting that reduced IL-6 levels may impair muscle contraction (1). Conversely, the proinflammatory effects of IL-6 may increase the migratory rate of SMCs (51). This indicates that the ketamine-caused decreasing IL- 6 is negatively correlated with the bladder stretching. Clinical observations have indicated that patients feel better and that their symptoms improve when they stop or reduce ketamine use. The observation that IL-6 expression was restored in the present study when ketamine treatment was removed or its concentration was reduced is consistent with these clinical observations. Therefore, ketamine abusers are strongly advised to terminate ketamine use. In addition, ketamine induced COL1 and COL2 deposition, and reduced IL-6 expression in SMCs; these effects may be associated with muscle contraction in the urinary bladder. In other words, the increased fibrosis and decreased myokine additionally cause the bladder dysfunction.

The ketamine-induced molecular alterations detected in SMCs may also include the inhibition of iNOS (48). There is evidence to suggest that reactive oxygen species are crucial to the pathogenesis of various diseases $(52,53)$. In a rat model, subanesthetic doses of ketamine increased oxidative stress and induced a schizophrenia-like condition (25). The effects of iNOS in response to oxidative stress were observed in epithelial cells (54). The findings of the present study, and those of other studies, suggested that the ketamine-induced 
cystitis may also result from a reduction in iNOS levels following treatment of SMCs with cyclic ketamine. However, in a previous study, selective inhibition of NOS could increase muscle thickness (55). The reduction in nitric oxide levels due to reduced iNOS may also increase smooth muscle contraction (e.g., frequency or strength) (56). Therefore, in ketamine abusers, cyclic ketamine treatment may lead to continuous muscle contraction and to the development of small bladder capacity due to iNOS downregulation. These findings indicated that reversing the effects of oxidative stress is a potential therapeutic strategy in addition to surgery.

CTX, which belongs to the group of oxazaphosphorines, exhibits strong activity against several experimental tumors and is widely used in the treatment of various clinical conditions, including lymphoproliferative disorders, small cell lung cancer, breast cancer and other severe forms of rheumatic diseases, such as lupus erythematosus, systemic sclerosis and vasculitis $(57,58)$. However, CTX and its isomeric analogue ifosfamide (IFS) can dose-dependently induce hemorrhagic cystitis, a urological disorder $(59,60)$. Following administration of CTX, iNOS bladder activity increases, which is associated with histopathological alterations (61). Ozguven et al reported that appropriate ketamine pretreatment attenuated experimental IFS-induced hemorrhagic cystitis in a rat model (62). This result suggested that IFS (or CTX) and ketamine have opposing effects on the urinary bladder, probably due to their different effects on iNOS activities. In the present study, the results observed in the ketamine-treated SMCs are consistent with the results of previous studies, which suggested that the production of proinflammatory mediators, such as IL-6 and free oxygen radicals (nitric oxide), are reduced in SMCs following ketamine treatment $(60,62)$.

It seems likely that ketamine-induced cystitis is propagated via an accumulation of molecular alterations in the urinary bladder, particularly in SMCs. These alterations may result in the clinical symptoms observed in ketamine abusers. A specific therapeutic agent, CTX, may counteract oxidative damage and reverse ketamine-induced aberrations (Fig. 6).

In conclusion, the findings of the present study provided a novel insight into the molecular mechanisms underlying ketamine-induced cystitis and may suggest novel clinical treatments.

\section{Acknowledgments}

The present study was supported by grants from the Cathay General Hospital (grant nos. CGH-MR-10022 and CGH-MR-A10316) to Y.-C.W.

\section{References}

1. Zarate C, Duman RS, Liu G, Sartori S, Quiroz J and Murck H: New paradigms for treatment-resistant depression. Ann NY Acad Sci 1292: 21-31, 2013.

2. Naughton M, Clarke G, O'Leary OF, Cryan JF and Dinan TG: A review of ketamine in affective disorders: Current evidence of clinical efficacy, limitations of use and pre-clinical evidence on proposed mechanisms of action. J Affect Disord 156: 24-35, 2014.

3. Kavalali ET and Monteggia LM: How does ketamine elicit a rapid antidepressant response? Curr Opin Pharmacol 20: 35-39, 2015.
4. Jha AK, Bhardwaj N, Yaddanapudi S, Sharma RK and Mahajan JK: A randomized study of surgical site infiltration with bupivacaine or ketamine for pain relief in children following cleft palate repair. Paediatr Anaesth 23: 401-406, 2013.

5. Tawfic QA: A review of the use of ketamine in pain management. J Opioid Manag 9: 379-388, 2013.

6. Ricaurte GA and McCann UD: Recognition and management of complications of new recreational drug use. Lancet 365 : 2137-2145, 2005

7. Wang YC, Chen SK and Lin CM: Breaking the drug addiction cycle is not easy in ketamine abusers. Int J Urol 17: 496, author reply $497,2010$.

8. Jansen KL and Darracot-Cankovic R: The nonmedical use of ketamine, part two: A review of problem use and dependence. J Psychoactive Drugs 33: 151-158, 2001.

9. Lim DK: Ketamine associated psychedelic effects and dependence. Singapore Med J 44: 31-34, 2003.

10. Slikker W Jr, Liu F, Rainosek SW, Patterson TA, Sadovova N, Hanig JP, Paule MG and Wang C: Ketamine-induced toxicity in neurons differentiated from neural stem cells. Mol Neurobiol 52: 959-969, 2015.

11. Gray T and Dass M: Ketamine cystitis: An emerging diagnostic and therapeutic challenge. Br J Hosp Med (Lond) 73: 576-579, 2012.

12. Gu D, Huang J, Yin Y, Shan Z, Zheng S and Wu P: Long-term ketamine abuse induces cystitis in rats by impairing the bladder epithelial barrier. Mol Biol Rep 41: 7313-7322, 2014.

13. Shahani R, Streutker C, Dickson B and Stewart RJ: Ketamine-associated ulcerative cystitis: A new clinical entity. Urology 69: 810-812, 2007.

14. Chu PS, Ma WK, Wong SC, Chu RW, Cheng CH, Wong S, Tse JM, Lau FL, Yiu MK and Man CW: The destruction of the lower urinary tract by ketamine abuse: A new syndrome? BJU Int 102: 1616-1622, 2008.

15. Colebunders B and Van Erps P: Cystitis due to the use of ketamine as a recreational drug: A case report. J Med Case Reports 2: 219, 2008.

16. Chu PS, Kwok SC, Lam KM, Chu TY, Chan SW, Man CW, Ma WK, Chui KL, Yiu MK, Chan YC, et al: 'Street ketamine'-associated bladder dysfunction: A report of ten cases. Hong Kong Med J 13: 311-313, 2007.

17. Chen $\mathrm{CH}$, Lee MH, Chen YC and Lin MF: Ketamine-snorting associated cystitis. J Formos Med Assoc 110: 787-791, 2011.

18. Cheung RY, Lee JH, Chan SS, Liu DW and Choy KW: A pilot study of urine cytokines in ketamine-associated lower urinary tract symptoms. Int Urogynecol J Pelvic Floor Dysfunct 25: $1715-1719,2014$

19. Smart C, Kabir M and Pati J: Treatment of ketamine-associated cystitis with chondroitin sulphate. Br J Nurs 22: S4, S6, S8-9, 2013.

20. Chuang SM, Liu KM, Li YL, Jang MY, Lee HH, Wu WJ, Chang WC, Levin RM and Juan YS: Dual involvements of cyclooxygenase and nitric oxide synthase expressions in ketamine-induced ulcerative cystitis in rat bladder. Neurourol Urodyn 32: 1137-1143, 2013.

21. Gu D, Huang J, Shan Z, Yin Y, Zheng S and Wu P: Effects of long-term ketamine administration on rat bladder protein levels: A proteomic investigation using two-dimensional difference gel electrophoresis system. Int J Urol 20: 1024-1031, 2013.

22. Baker SC, Stahlschmidt J, Oxley J, Hinley J, Eardley I, Marsh F, Gillatt D, Fulford S and Southgate J: Nerve hyperplasia: A unique feature of ketamine cystitis. Acta Neuropathol Commun 1: 64, 2013.

23. Jhang JF, Hsu YH, Jiang YH and Kuo HC: Elevated serum IgE may be associated with development of ketamine cystitis. J Urol 192: 1249-1256, 2014.

24. Mami I, Tavernier Q, Bouvier N, Aboukamis R, Desbuissons G, Rabant M, Poindessous V, Laurent-Puig P, Beaune P, Tharaux PL, et al: A novel extrinsic pathway for the unfolded protein response in the kidney. J Am Soc Nephrol 27: 2670-2683, 2016.

25. de Oliveira L, Spiazzi CM, Bortolin T, Canever L, Petronilho F, Mina FG, Dal-Pizzol F, Quevedo J and Zugno AI: Different sub-anesthetic doses of ketamine increase oxidative stress in the brain of rats. Prog Neuropsychopharmacol Biol Psychiatry 33: 1003-1008, 2009.

26. Toma JG, Akhavan M, Fernandes KJ, Barnabé-Heider F, Sadikot A, Kaplan DR and Miller FD: Isolation of multipotent adult stem cells from the dermis of mammalian skin. Nat Cell Biol 3: 778-784, 2001. 
27. Fernandes KJ, McKenzie IA, Mill P, Smith KM, Akhavan M, Barnabé-Heider F, Biernaskie J, Junek A, Kobayashi NR, Toma JG, et al: A dermal niche for multipotent adult skin-derived precursor cells. Nat Cell Biol 6: 1082-1093, 2004.

28. Huang HI, Chen SK, Ling QD, Chien CC, Liu HT and Chan SH: Multilineage differentiation potential of fibroblast-like stromal cells derived from human skin. Tissue Eng Part A 16: 1491-1501, 2010.

29. Wang CC, Weng TI, Wu ET, Wu MH, Yang RS and Liu SH: Involvement of interleukin-6-regulated nitric oxide synthase in hemorrhagic cystitis and impaired bladder contractions in young rats induced by acrolein, a urinary metabolite of cyclophosphamide. Toxicol Sci 131: 302-310, 2012

30. Moore KA, Sklerov J, Levine B and Jacobs AJ: Urine concentrations of ketamine and norketamine following illegal consumption. J Anal Toxicol 25: 583-588, 2001.

31. Ho YH, Wang CC, Hsiao YT, Ko WK and Wu SM: Analysis of ten abused drugs in urine by large volume sample stacking-sweeping capillary electrophoresis with an experimental design strategy. J Chromatogr A 1295: 136-141, 2013.

32. Tam YH, Ng CF, Pang KK, Yee CH, Chu WC, Leung VY, Wong GL, Wong VW, Chan HL and Lai PB: One-stop clinic for ketamine-associated uropathy: Report on service delivery model, patients' characteristics and non-invasive investigations at baseline by a cross-sectional study in a prospective cohort of 318 teenagers and young adults. BJU Int 114: 754-760, 2014.

33. Ng CM, Ma WK, To KC and Yiu MK: The Chinese version of the pelvic pain and urgency/frequency symptom scale: A useful assessment tool for street-ketamine abusers with lower urinary tract symptoms. Hong Kong Med J 18: 123-130, 2012

34. Chung SD, Wang CC and Kuo HC: Augmentation enterocystoplasty is effective in relieving refractory ketamine-related bladder pain. Neurourol Urodyn 33: 1207-1211, 2014.

35. Lin HC, Lee HS, Chiueh TS, Lin YC, Lin HA, Lin YC, Cha TL and Meng E: Histopathological assessment of inflammation and expression of inflammatory markers in patients with ketamine-induced cystitis. Mol Med Rep 11: 2421-2428, 2015

36. Shen CH, Wang ST, Lee YR, Liu SY, Li YZ, Wu JD, Chen YJ and Liu YW: Biological effect of ketamine in urothelial cell lines and global gene expression analysis in the bladders of ketamine injected mice. Mol Med Rep 11: 887-895, 2015.

37. Andersson KE and Arner A: Urinary bladder contraction and relaxation: Physiology and pathophysiology. Physiol Rev 84 935-986, 2004.

38. Ibeawuchi CU, Ajayi OI and Ebeigbe AB: Vascular effect of ketamine in isolated rabbit aortic smooth muscle. Niger J Physiol Sci 23: 85-88, 2008

39. Ozturk AM, Ergun MA, Demir T, Gungor I, Yilmaz A and Kaya K: Ketamine is toxic to chondrocyte cell cultures. Bone Joint J 96-B: 989-994, 2014.

40. Chang HC, Chen TL and Chen RM: Cytoskeleton interruption in human hepatoma HepG2 cells induced by ketamine occurs possibly through suppression of calcium mobilization and mitochondrial function. Drug Metab Dispos 37: 24-31, 2009.

41. Ma J, Nishimura H, Fogo A, Kon V, Inagami T and Ichikawa I: Accelerated fibrosis and collagen deposition develop in the renal interstitium of angiotensin type 2 receptor null mutant mice during ureteral obstruction. Kidney Int 53: 937-944, 1998.

42. Juan YS, Lee YL, Long CY, Wong JH, Jang MY, Lu JH, Wu WJ, Huang YS, Chang WC and Chuang SM: Translocation of NF- $\mathrm{KB}$ and expression of cyclooxygenase-2 are enhanced by ketamine-induced ulcerative cystitis in rat bladder. Am J Pathol 185: 2269-2285, 2015

43. Song M, Yu HY, Chun JY, Shin DM, Song SH, Choo MS and Song YS: The fibrosis of ketamine, a noncompetitive $\mathrm{N}$-methyl-d-aspartic acid receptor antagonist dose-dependent change in a ketamine-induced cystitis rat model. Drug Chem Toxicol 39: 206-212, 2016.

44. Chen CZ and Raghunath M: Focus on collagen: In vitro systems to study fibrogenesis and antifibrosis state of the art. Fibrogenesis Tissue Repair 2: 7, 2009.

45. Borg BB, Seetharam A, Subramanian V, Basha HI, Lisker-Melman M, Korenblat K, Anderson CD, Shenoy S, Chapman WC, Crippin JS, et al: Immune response to extracellular matrix collagen in chronic hepatitis C-induced liver fibrosis. Liver Transpl 17: 814-823, 2011.
46. Challa AA, Vukmirovic M, Blackmon J and Stefanovic B Withaferin-A reduces type I collagen expression in vitro and inhibits development of myocardial fibrosis in vivo. PLoS One 7: e42989, 2012

47. Muñoz-Cánoves P, Scheele C, Pedersen BK and Serrano AL: Interleukin-6 myokine signaling in skeletal muscle: A double-edged sword? FEBS J 280: 4131-4148, 2013.

48. Yang C, Jiang RY, Shen J, Hong T, Liu N, Ding LC, Wang DM, Chen LJ, Xu B and Zhu B: Ketamine attenuates the lipopolysaccharide-induced inflammatory response in cultured N2a cells. Mol Med Rep 8: 217-220, 2013.

49. Tang SH, Yu JG, Li JJ and Sun JY: Neuroprotective effect of ketamine on acute spinal cord injury in rats. Genet Mol Res 14 3551-3556, 2015

50. Lee GL, Wu JY, Yeh CC and Kuo CC: TLR4 induces CREB-mediated IL-6 production via upregulation of F-spondin to promote vascular smooth muscle cell migration. Biochem Biophys Res Commun 473: 1205-1210, 2016.

51. Hiram R, Rizcallah E, Marouan S, Sirois C, Sirois M, Morin C, Fortin S and Rousseau E: Resolvin E1 normalizes contractility, $\mathrm{Ca}^{2+}$ sensitivity and smooth muscle cell migration rate in TNF- $\alpha$-and IL-6-pretreated human pulmonary arteries. Am J Physiol Lung Cell Mol Physiol 309: L776-L788, 2015.

52. Cascella R, Ragazzo M, Strafella C, Missiroli F, Borgiani P, Angelucci F, Marsella LT, Cusumano A, Novelli G, Ricci F, et al: Age-related macular degeneration: Insights into inflammatory genes. J Ophthalmol 2014: 582842, 2014.

53. Ye ZW, Zhang J, Townsend DM and Tew KD: Oxidative stress, redox regulation and diseases of cellular differentiation. Biochim Biophys Acta 1850: 1607-1621, 2015.

54. Dijkstra G, Blokzijl H, Bok L, Homan M, van Goor H, Faber KN, Jansen PL and Moshage H: Opposite effect of oxidative stress on inducible nitric oxide synthase and haem oxygenase-1 expression in intestinal inflammation: Anti-inflammatory effect of carbon monoxide. J Pathol 204: 296-303, 2004

55. Soyer T, Boybeyi Ö and Atasoy P: Selective inhibition of nitric oxide synthase causes increased muscle thickness in rat esophagus. J Pediatr Surg 50: 1112-1114, 2015.

56. Al-Azemi M, Refaat B, Amer S, Ola B, Chapman N and Ledger W: The expression of inducible nitric oxide synthase in the human fallopian tube during the menstrual cycle and in ectopic pregnancy. Fertil Steril 94: 833-840, 2010.

57. Dobrek $Ł$ and Thor PJ: Bladder urotoxicity pathophysiology induced by the oxazaphosphorine alkylating agents and its chemoprevention. Postepy Hig Med Dosw Online 66: 592-602, 2012.

58. Yilmaz N, Emmungil H, Gucenmez S, Ozen G, Yildiz F, Balkarli A, Kimyon G, Coskun BN, Dogan I, Pamuk ON, et al: Incidence of cyclophosphamide-induced urotoxicity and protective effect of mesna in rheumatic diseases. J Rheumatol 42 1661-1666, 2015.

59. Gray KJ, Engelmann UH, Johnson EH and Fishman IJ: Evaluation of misoprostol cytoprotection of the bladder with cyclophosphamide (Cytoxan) therapy. J Urol 136: 497-500, 1986.

60. Wang N, Yu HY, Shen XF, Gao ZQ, Yang C, Yang JJ and Zhang GF: The rapid antidepressant effect of ketamine in rats is associated with downregulation of pro-inflammatory cytokines in the hippocampus. Ups J Med Sci 120: 241-248, 2015

61. Souza-Fiho MV, Lima MV, Pompeu MM, Ballejo G, Cunha FQ and Ribeiro RdeA: Involvement of nitric oxide in the pathogenesis of cyclophosphamide-induced hemorrhagic cystitis. Am J Pathol 150: 247-256, 1997.

62. Ozguven AA, Yilmaz O, Taneli F, Ulman C, Vatansever S and Onag A: Protective effect of ketamine against hemorrhagic cystitis in rats receiving ifosfamide. Indian J Pharmacol 46: 147-151, 2014.

This work is licensed under a Creative Commons Attribution-NonCommercial-NoDerivatives 4.0 International (CC BY-NC-ND 4.0) License. 